\title{
High-rate behaviour of iron ore pellet
}

\author{
Gustaf Gustafsson $^{1, \text { a }}$, Hans-Åke Häggblad ${ }^{1}$, Pär Jonsén ${ }^{1}$, and Masahiro Nishida ${ }^{2}$ \\ ${ }^{1}$ Luleå University of Technology, Division of Mechanics of Solid Materials, 97187 Luleå, Sweden \\ ${ }^{2}$ Nagoya Institute of Technology, Gokiso-cho, Showa-ku, Aichi 466-8555, Japan
}

\begin{abstract}
Iron ore pellets are sintered, centimetre-sized spheres of ore with high iron content. Together with carbonized coal, iron ore pellets are used in the production of steel. In the transportation from the pelletizing plants to the customers, the iron ore pellets are exposed to different loading situations, resulting in degradation of strength and in some cases fragmentation. For future reliable numerical simulations of the handling and transportation of iron ore pellets, knowledge about their mechanical properties is needed. This paper describes the experimental work to investigate the dynamic mechanical properties of blast furnace iron ore pellets. To study the dynamic fracture of iron ore pellets a number of split Hopkinson pressure bar tests are carried out and analysed.
\end{abstract}

\section{Introduction}

Handling of iron ore pellets is an important part in the production chain for many producers of iron ore pellets. Knowledge about this sub process is very important for further improved efficiency and increased product quality. After production in the pelletizing plants, the iron ore pellets pass through a number of transportation and handling systems like conveyor belts, silo filling, silo discharging and transport by rail and ship. During these treatments, the pellets are exposed to different loadings, resulting in degradation of their strength and generation of fines. To study and optimize processes of transportation and handling of bulk material, traditionally half- or full-scale experiments have been used [1,2]. The focus of these studies is often the pressures on the surrounding structures and not the stresses in the bulk material. Numerical simulations of these processes give a possibility to study the processes in more detail. Most of the work so far in simulation and constitutive modelling of granular materials like soils [3] and metal powders [4,5] is carried out with continuum based methods like the finite element (FE) method. For iron ore pellets flow particle based methods like the smoothed particle hydrodynamics (SPH) method [6] can be used. Such models give the flow, stresses and strains on a continuum length scale but not the stress state inside the individual granules. To study the local contact behaviour of compressed granular material, detailed models of the individual particles are necessary. Such models are available for some granular materials in 2D, see for example [7] and for static loading of pellets, see [8].

This paper describes the experimental work to investigate dynamic mechanical properties for blast furnace iron ore pellets. The data for single iron ore pellets worked out in this paper could be used to model the individual particles in an assembly.

\footnotetext{
${ }^{a}$ Corresponding author: gustaf .gustaf sson@1tu.se
}

\section{Theoretical considerations}

Iron ore pellets are a hard and brittle porous material and can be compared with materials like rocks and ceramics. Theories developed for these materials have been used in this study.

\subsection{Compression of an irregular sphere}

A theoretical and practical study of the stress state in an irregular sphere-like test piece subjected to the point load test is given in [9]. The results show that the stress state in an irregular test piece subjected to concentrated loads may be, in the vicinity of the axis of loading, much the same as that in a perfectly spherical test piece compressed diametrically. According to their results the maximum tensile strength, $S_{t}$ for an irregular test piece occur near the centre and is approximately given by

$$
S_{t}=c \frac{2 F}{\pi D^{2}}
$$

where $F$ is the applied force and $D$ is the distance between the points of loading. The constant $c$ is experimentally determined and takes a value between 1.21 and 1.36 in the centre of the test piece for rock materials. For more details, see [9].

As a measure of the irregularity of the specimens, a shape index, $\eta$, is derived. The distance, $D$, is divided by the average diameter, $\bar{D}$, of the specimens according

$$
\eta=\frac{D}{\bar{D}}
$$

The average diameter is calculated as the diameter of a sphere with the same mass, $M$, and density, $\rho$, as the specimen.

$$
\bar{D}=\sqrt[3]{\frac{6 M}{\pi \rho}} .
$$



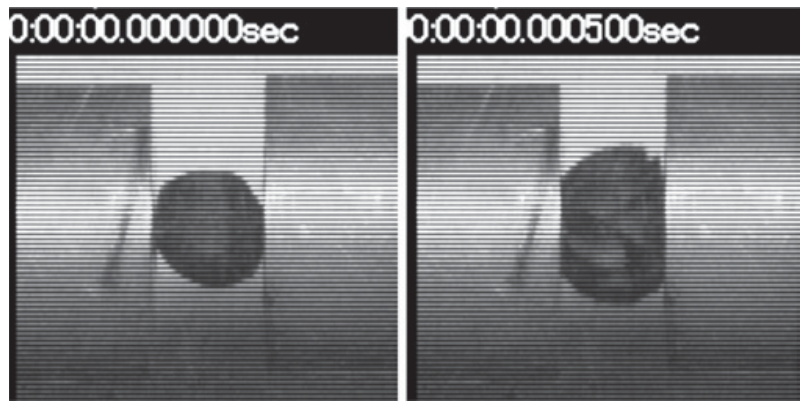

Figure 1. Iron ore pellet before loading (left) and after breakage (right).

\subsection{Statistical measures}

Some of the data analysed will be expressed in terms of the statistical expectation values $\mu$, standard deviations $S$, confidence intervals and prediction intervals. Assuming a normal distribution, the $95 \%$ confidence interval and $95 \%$ prediction interval are given by Eqs. (4) and (5), respectively

$$
\begin{gathered}
\hat{\mu}-1.96 \frac{S}{\sqrt{N}}<\mu<\hat{\mu}+1.96 \frac{S}{\sqrt{N}} \\
\hat{\mu}-1.96 S<x<\hat{\mu}+1.96 S .
\end{gathered}
$$

Where $\hat{\mu}$ is an estimate of the expectation value, $x$ is the measured data, $N$ is the number of tests and $S$ is the standard deviation, according to

$$
\begin{gathered}
\hat{\mu}=\frac{1}{N} \sum_{i=1}^{N} X_{i} \\
S=\sqrt{\frac{1}{N} \sum_{i=1}^{N}\left(x_{i}-\bar{x}\right)^{2} .}
\end{gathered}
$$

\section{Materials and methods}

The material tested is iron ore pellets from LKAB (Luossavaara-Kiirunavaara AB) in Malmberget, Sweden. In the blast furnace, iron ore is reduced and smelted to liquid crude iron. Fine-grained iron ore is too fine material for burdening in the blast furnace and must therefore be sintered into larger entities. Iron ore pellets are sintered, centimetre-sized spheres of grained ore with high iron content $(\approx 67 \mathrm{wt} \% \mathrm{Fe})$.

\subsection{Tested iron ore pellets}

To obtain a more consistent quality and material characteristics in the iron ore pellets test samples, laboratory produced pellets are used in this study. In the laboratory, the iron ore pellets are produced in a smallscale pelletizing process including all the steps in the pelletizing plants. In the last step the iron ore pellets are sintered in batches of about $50 \mathrm{~kg}$. In the laboratory production, the iron ore pellets are handled more careful and the production parameters are better controlled. The sizes of the iron ore pellets are screened out to a range of $9 \mathrm{~mm}$ to $12 \mathrm{~mm}$ before testing. See Fig. 1 for an iron

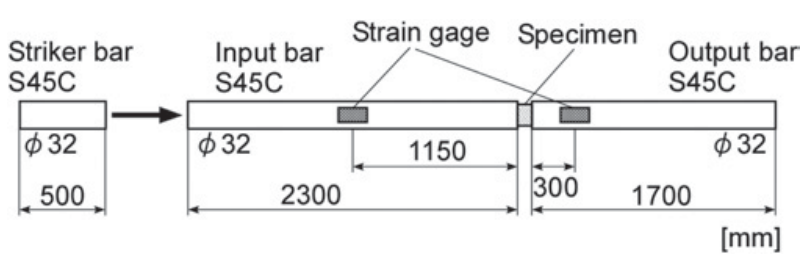

Figure 2. Experimental set-up for split Hopkinson pressure bar (SHPB) tests.

Table 1. Material constants of SHPB input and output bars.

\begin{tabular}{|c|c|c|}
\hline Density & $\begin{array}{c}\text { Elastic wave velocity } \\
\text { of the input/output bar, } \\
c_{b}\end{array}$ & Young's modulus, $E$ \\
\hline $7.85 \mathrm{~g} / \mathrm{cm}^{3}$ & $5110 \mathrm{~m} / \mathrm{s}$ & $208 \mathrm{GPa}$ \\
\hline
\end{tabular}

Table 2. Test descriptions and specimen data.

\begin{tabular}{|c|c|c|c|c|}
\hline $\begin{array}{c}\text { Test } \\
\text { serie }\end{array}$ & $\begin{array}{c}\text { Number of } \\
\text { specimens }\end{array}$ & $\begin{array}{c}\text { Mass, } \\
\mathrm{M},[\mathrm{g}] \\
\text { average } \pm S\end{array}$ & $\begin{array}{c}\text { Diameter, } \\
\mathrm{D},[\mathrm{mm}] \\
\text { average } \pm S\end{array}$ & $\begin{array}{c}\text { Shape } \\
\text { index, } \eta \\
\text { average } \pm S\end{array}$ \\
\hline 1 & 10 & $3.22 \pm 0.51$ & $11.88 \pm 0.69$ & $1.01 \pm 0.054$ \\
\hline 2 & 8 & $3.17 \pm 0.46$ & $11.24 \pm 0.76$ & $0.95 \pm 0.044$ \\
\hline 3 & 10 & $3.29 \pm 0.32$ & $11.72 \pm 0.30$ & $0.98 \pm 0.039$ \\
\hline 4 & 13 & $3.05 \pm 0.41$ & $11.50 \pm 0.60$ & $0.99 \pm 0.045$ \\
\hline 5 & 30 & $2.95 \pm 0.52$ & $11.67 \pm 0.71$ & $1.02 \pm 0.045$ \\
\hline
\end{tabular}

ore pellet from one of the dynamic tests. The average density for the tested pellets batch was measured to $\rho=3.69 \mathrm{~kg} / \mathrm{m}^{3}$.

\subsection{Split Hopkinson pressure bar load tests}

Dynamic testing of iron ore pellet is carried out using the split Hopkinson pressure bar (SHPB) assembly. The input and output bars for the SHPB experiments were made of steel, and their diameter and length were $32 \mathrm{~mm}$ and $2300 \mathrm{~mm} / 1700 \mathrm{~mm}$ respectively. Strain gages were put on both sides of input bar and output bar $1150 \mathrm{~mm}$ and $300 \mathrm{~mm}$ away from the specimen, see Fig. 2. The compressive force histories of specimens were calculated from the strain of bars measured by the strain gages based on the following equation [10]:

$$
F(t)=A E\left[\varepsilon_{i}(t)+\varepsilon_{r}(t)+\varepsilon_{t}(t)\right]
$$

where $\varepsilon_{i}, \varepsilon_{r}$ and $\varepsilon_{t}$ are the axial strains in the input bar induced by the incident wave and reflected wave from the specimen and the axial strain in the output bar induced by the transmitted wave. $E$ is Young's modulus and $A$ is the areas of the input and output bars. Material constants of the steel bars used in the calculation are shown in Table 1. A steel striker with a diameter of $32 \mathrm{~mm}$ and a length of $500 \mathrm{~mm}$ was used in the tests. A summation of the sizes and number of specimens for the test series are shown in Table 2.

\section{Experimental results and discussion}

The shape of the iron ore pellets is not perfectly spherical; they have an irregular smooth shape. Nor do all iron ore pellets have the same size as shown in Table 1 . The 


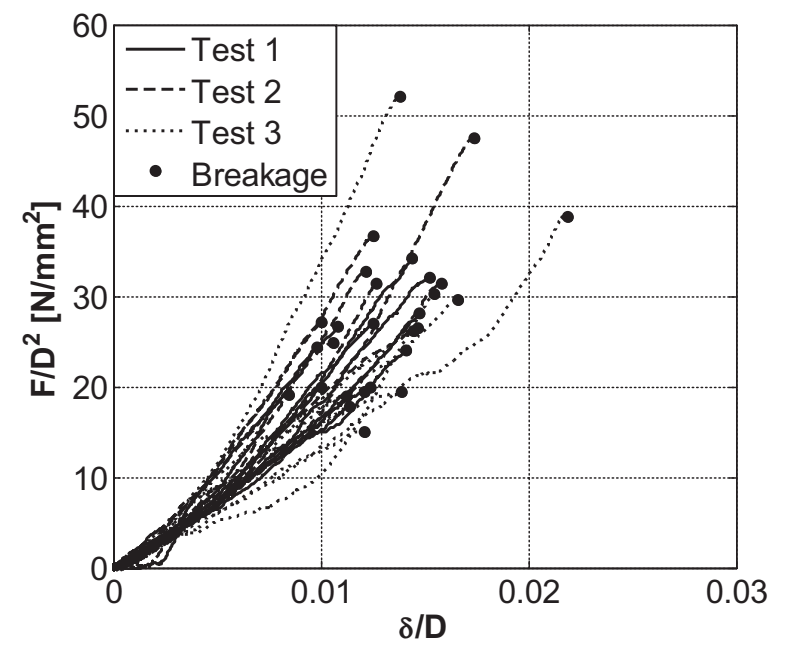

Figure 3. Load versus displacement including fracture. Test series $1-3$.

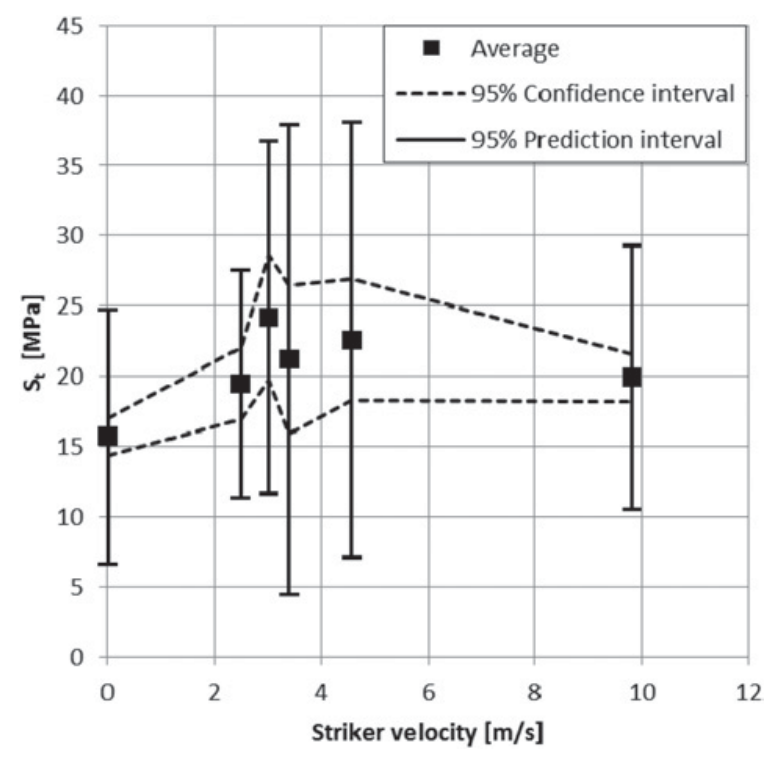

Figure 4. Fracture strength $\left(S_{t}\right)$ as function of striker velocity. Average breakage level with $95 \%$ confidence interval and $95 \%$ prediction interval. Static data from reference [11].

diameter, $D$, is defined as the distance between the loading points at each test.

Dynamic tests of 71 iron ore pellets with five different striker velocities are carried out. The load displacement curves for some of the experiments are shown in Fig. 3. To compensate for size variations the load, $F$, is divided by $D^{2}$ resulting in a stress-like measure and the displacement, $\delta$, is divided by $D$ resulting a strain measure. The fractures are indicated with dots.

The stress state in the centre of the specimen is assumed be compressive in the loading direction and tension perpendicular to this direction. Using $\mathrm{c}=1.21$ in Eq. (1) gives the tension stress values. The average fracture
Table 3. Results of dynamic test series.

\begin{tabular}{|l|l|c|l|l|}
\hline $\begin{array}{l}\text { Test } \\
\text { serie }\end{array}$ & $\begin{array}{l}\text { Striker } \\
\text { velocity, } v \\
{[\mathrm{~m} / \mathrm{s}]} \\
\text { average } \pm S\end{array}$ & $\begin{array}{l}\text { Deformation } \\
\text { velocity, } \\
\dot{\delta} / D,[1 / \mathrm{s}] \\
\text { average }\end{array}$ & $\begin{array}{l}\text { Fracture } \\
\text { load, } F / D^{2} \\
{\left[\mathrm{~N} / \mathrm{mm}^{2}\right]} \\
\text { average } \pm S\end{array}$ & $\begin{array}{l}\text { Fracture } \\
\text { strength, } S_{t} \\
{[\mathrm{MPa}]} \\
\text { average } \pm S\end{array}$ \\
\hline 1 & $2.49 \pm 0.017$ & 172 & $25.3 \pm 5.36$ & $19.5 \pm 4.13$ \\
\hline 2 & $3.01 \pm 0.007$ & 213 & $31.5 \pm 8.34$ & $24.2 \pm 6.42$ \\
\hline 3 & $3.38 \pm 0.070$ & 223 & $27.5 \pm 11.1$ & $21.2 \pm 8.54$ \\
\hline 4 & $4.56 \pm 0.044$ & 277 & $29.4 \pm 10.3$ & $22.6 \pm 7.92$ \\
\hline 5 & $9.82 \pm 0.076$ & 723 & $25.8 \pm 6.20$ & $19.9 \pm 4.78$ \\
\hline
\end{tabular}

load and fracture strength are shown in Table 3, see also Fig. 4. In Table 3 is also the deformation velocity given, it can be interpreted as a measure of the strain rate.

\section{Conclusions}

This investigation has provided some new knowledge about the mechanical properties and behaviour of iron ore pellets. From the experimental measurements, fracture strength are evaluated for different deformation velocities and determined in terms of statistical means and confidence intervals. The results of this study show that the stiffness seems to be approximately the same for the tested range of deformation velocities and the fracture strength show a small decrease with increased deformation velocity. Compared to data from quasi-static testing the fracture strength is increased with approximate $35 \%$.

\section{References}

[1] C.F. Chen, J.M. Rotter, J.Y. Ooi, Z. Zhong, Chemical Engineering Science, 60, 3029-3041 (2005)

[2] J.Y. Ooi, J.F. Chen, J.M. Rotter, Powder Technology, 99, 272-284 (1998)

[3] W.F. Chen, E. Mizuno, Nonlinear analysis in soil mechanics (Elsevier, Netherlands, 1990)

[4] P.R. Brewin, O. Coube, P. Doremus, J.H. Tweed, Modelling of powder die compaction (Springer, London, 2008)

[5] P. Jonsén, H.-Å. Häggblad, Journal of Solids and Structures. 44, 6398-6411 (2007)

[6] G. Gustafsson, H. Häggblad, M. Oldenburg, NUMIFORM 2007, 1483-1488 (2007)

[7] D.T. Gethin, R.S. Ransing, R.W. Lewis, M. Dutko, A.J.L. Crook, Computers and Structures, 79, 1287-1294 (2001)

[8] G. Gustafsson, H.-Å. Häggblad, P. Jonsén, Powder Technology, 239, 231-238 (2013)

[9] Y. Hiramatsu, Y. Oka, International Journal of Rock Mechanics and Mining Science, 3, 89-99 (1966)

[10] W. Chen, and B. Song, Split Hopkinson (Kolsky) bar: design, testing and applications (Springer 2010)

[11] G. Gustafsson, H.-Å. Häggblad, P. Jonsén, Powder Technology, 235, 126-135 (2013) 